\title{
Treatment of Soil-Washing Effluents Polluted with Herbicide Oxyfluorfen by Combined Biosorption-Electrolysis
}

\author{
Khaoula Chair, $^{\dagger}$ Ahmed Bedoui, ${ }^{\dagger}$ Nasr Bensalah, ${ }^{\ddagger}$ Cristina Sáez, ${ }^{\S}{ }^{\circledR}$ Francisco J. Fernández-Morales, ${ }^{\S}$ \\ Salvador Cotillas, ${ }^{\| \odot}$ Pablo Cañizares, ${ }^{\S}$ and Manuel A. Rodrigo ${ }^{*}, \S(0)$ \\ ${ }^{\dagger}$ Department of Chemistry, Faculty of Sciences of Gabes, University of Gabes, Gabes, Tunisia \\ ${ }^{\ddagger}$ Department of Chemistry and Earth Sciences, College of Arts and Science, Qatar University, 2713 Doha, Qatar \\ ${ }^{\S}$ Department of Chemical Engineering, Faculty of Chemical Sciences \& Technologies, Universtiy of Castilla-La Mancha, Enrique \\ Costa Building, Campus Universitario s/n, 13071 Ciudad Real, Spain \\ "Department of Chemical Engineering, School of Industrial Engineering, University of Castilla-La Mancha, Campus Universitario s/n, \\ 02071 Albacete, Spain
}

\begin{abstract}
The treatment of soil-washing effluents polluted with herbicide oxyfluorfen is studied using a combined process consisting of biosorption and electrolysis. Results show that oxyfluorfen is very efficiently removed from synthetic soil by soil washing with sodium dodecyl sulfate (SDS). The effluent can be treated by biosorption with fresh activated sludge coming from a municipal wastewater treatment plant, and the maximum adsorption capacity of this activated sludge was found to be $18 \mathrm{mg}$ of oxyfluorfen per gram of biomass. Biosorption fits well to a type I adsorption isotherm. Effluents of the biosorption process underwent anodic oxidation, photoelectrolysis, and sonoelectrolysis at high and low frequency. The four technologies were able to mineralize completely the effluent, although important differences arose during the treatment which depended significantly on the application of ultrasound or ultraviolet irradiation and on the release of sulfate from the oxidation of SDS: intermediates were removed faster because of the activation of sulfate radicals. Oxyfluorfen and its oxidation intermediates are removed faster than SDS, and when they are fully depleted there are still large concentrations of SDS in the treated solution. This opens the possibility of reusing the soil washing fluid.
\end{abstract}

\section{INTRODUCTION}

Herbicides are chemical substances widely used in agriculture to improve productivity of crops. ${ }^{1}$ They have outstanding importance, and without them crop yield could drop hugely and food prices would increase, at least, in the same ratio. Typically, herbicides are xenobiotic and toxic and do not easily biodegrade. They are strongly adsorbed to different types of soil, but after a certain period they can be leached into surface or groundwater. Consequently, they can cause serious problems to human health and environment.

Currently, one of the most applied herbicides is oxyfluorfen, which is a diphenyl ether used to control certain annual broadleaf and grassy weeds. Oxyfluorfen is moderately persistent in soil, ${ }^{2-4}$ with a half-life of about 30 to 40 days. It has low water solubility $\left(0.116 \mathrm{mg} \mathrm{dm}^{-3}\right.$ at $\left.20^{\circ} \mathrm{C}\right)$, and low vapor pressure $\left(0.026 \mathrm{mPa}\right.$ at $\left.25^{\circ} \mathrm{C}\right)$. Its runoff may seriously impact water reservoirs ${ }^{5,6}$, and it is associated with serious health problems such as cancer, central nervous system disorders, birth defects, genetic mutation, sterility, and even death. $^{7}$ It is removed naturally by photodegradation ${ }^{8}$ and bioremediation $^{9-11}$ and typically, it is very well-sorbed to most soils. ${ }^{12,13}$ However, the low rate of these processes may explain that a part of oxyfluorfen can be leached into surface and groundwater. Then, it is necessary to search for effective methods capable of completely removing this pollutant from soils as fast as possible, before their runoff reaches natural water bodies.

Soil washing can easily accomplish the removal of oxyfluorfen from soils, because it is a low-cost, very simple and rapid process, which is performed at mild operating conditions. ${ }^{14-16}$ Surfactants-aided soil washing (SASW) can completely remediate soils contaminated with organic pollutants, transferring the pollution of soil to a washing fluid, which becomes a highly polluted wastewater containing a complex mixture of dissolved organics and surfactants, colloids, and inorganic salts. Recently, biosorption has gained increasing interest for the removal of organic and inorganic pollutants from different wastewaters. $^{17,18}$ Biosorption involves the use of biological materials that extract organic pollutants from soils using their ligands or functional groups. The use of biosorbents is a very competitive approach because it is inexpensive and green, and the biosorbents have high adsorption capability. The treatment of soils contaminated with herbicides by biosorption can

Received: December 24, 2016

Revised: February 2, 2017

Accepted: February 3, 2017

Published: February 6, 2017 
transfer the pollutants from soil washing effluents to water that can be easily treated. The resulting wastewater containing herbicides can be treated by advanced oxidation processes. Advanced oxidation processes are one of the most effective processes for cleaning polluted herbicide wastewater. ${ }^{19}$ These processes are highly efficient methods for wastewater treatment because of the ability to mineralize a wide range of recalcitrant organic contaminants by generating highly reactive hydroxyl radicals. Particularly, the electro-oxidation process has received increasing attention because of its ability to reach complete mineralization of the organics into carbon dioxide, water, and inorganics ions. ${ }^{15,20,21}$

This work aims to investigate the remediation of soils spiked with oxyfluorfen by a combination of surfactant-aided soil washing and biosorption on activated sludge. The wastewater produced by soil washing/biosorption of spiked soils is then treated by electrochemical anodic oxidation ( $\mathrm{AO}$ ) and electrochemically irradiated oxidation using $\mathrm{AO}$ with borondoped diamond (BDD) anodes combined with UV light irradiation (PE) and low and high frequency ultrasounds (LFSE, HF-SE). This process was previously evaluated for herbicide $2,4-\mathrm{D}^{22}$ and in this case, the main difference is the much lower solubility of oxyfluorfen, which requires the use of surfactants in the soil washing fluid to efficiently remove the pollutant and produces a waste with a significant concentration of micelles.

\section{MATERIALS AND METHODS}

Chemicals. In this work, clay was selected as the model soil. Oxyfluorfen was selected as the model organic compounds, and it was purchased from Sigma-Aldrich. Deionized water was used to prepare all solutions. Sodium dodecyl sulfate (SDS) (Fluka, Spain) was used as solubilizing agent, while hexane and ethyl acetate (Sigma-Aldrich, Spain) were used as solvent for extraction of liquid and solid samples.

Preparation of Synthetic Groundwater. Synthetic groundwater was used as the solvent of the soil washing process. It was prepared by dissolving $6.671 \mathrm{~g}$ of $\mathrm{MgSO}_{4} \cdot 7 \mathrm{H}_{2} \mathrm{O}$, $1.318 \mathrm{~g}$ of $\mathrm{NaCl}, 1.302 \mathrm{~g}$ of $\mathrm{NaNO}_{3}, 0.255 \mathrm{~g}$ of $\mathrm{KI}$, and $2.497 \mathrm{~g}$ of $\mathrm{CaCO}_{3}$ in $10 \mathrm{dm}^{3}$ of deionized water. SDS from 5 to $20 \mathrm{~g}$ $\mathrm{dm}^{-3}$ was added as solubilizing agent.

Preparation of Spiked Soil. The preparation of soil has been described in the literature elsewhere. ${ }^{23-25}$ Polluted soil was prepared by dissolving oxyfluorfen in hexane and then mixing this solution with clay soil. The spiked clay was aerated for 1 day to favor evaporation of the hexane. In this way the oxyfluorfen was homogeneously distributed on the clay surface. The resulting oxyfluorfen concentration in the soil was $0.5 \mathrm{~g}$ $\mathrm{kg}^{-1}$ of soil. Table 1 shows the main characteristics of the soil used in this work.

Soil-Washing Procedure. Soil washing with SDS solutions was carried out in a $20 \mathrm{dm}^{3}$ stirred tank and operated in discontinuous mode. A $2 \mathrm{~kg}$ sample of polluted soil $(0.5 \mathrm{~g}$ of oxyfluorfen $\mathrm{kg}^{-1}$ of soil) was stirred with $8 \mathrm{dm}^{3}$ SDS solution for $24 \mathrm{~h}$ at a stirring rate of $150 \mathrm{rpm}$. Then, the mixture was decanted for $12 \mathrm{~h}$ to separate the soil from the aqueous phase.

Biosorption of Soil-Washing Effluents. Batch biosorption experiments were performed in order to evaluate the potential application of this technology for herbicides removal from liquid samples. In each experiment, fresh activated sludge from a conventional Wastewater Treatment Facility located in Ciudad Real, was added to the soil washing fluid (SWF). Before each test, the batch reactors were purged with nitrogen in order
Table 1. Classification and Composition of Soil by USCS

\begin{tabular}{lc}
\multicolumn{1}{c}{ mineral } & $\%$ \\
glauconite & 24 \\
kaolinite & 23 \\
montmorillonite & 20 \\
quartz & 12 \\
muscovite & 8 \\
feldspar & 6 \\
illite & 6 \\
calcite & 1 \\
smectite & \\
& \\
liquid limit & parameters \\
plastic limit & 42 \\
plasticity index & 24 \\
USCS code & 18 \\
low plasticity clay & $\mathrm{CL}$ \\
\hline
\end{tabular}

to remove the oxygen from the gas phase. Working in this way, the removal of herbicide by means of aerobic oxidation of herbicide was avoided. The batch reactors were located in an incubator in order to maintain the temperature at about $20^{\circ} \mathrm{C}$. The batch reactors were mixed by means of a magnetic stirrer rotating at $100 \mathrm{rpm}$ in order to maintain the biomass suspended, but minimizing mass transfer between the liquid and gas phases. The ratio of biomass/herbicide used was 20 . Once the adsorption tests were finished, after $6 \mathrm{~h}$ of contact time, the biomass was separated from the solutions by means of filtration through a glass fiber filter. The liquid phase was then treated by electrochemical, sonoelectrochemical, and photoelectrochemical processes.

The herbicide was recovered and sorbate uptake was calculated with reference to concentrations detected in noninoculated media. The sorbate uptake was calculated using eq 1 , where $q$ corresponds to the sorbate uptake, $V$ is the liquid volume $(\mathrm{L}), C_{\mathrm{i}}$ and $C_{\mathrm{f}}$ are the initial and final herbicide concentrations, and $S$ is the sorbent amount $(\mathrm{g})$.

$$
q=\frac{V\left(C_{\mathrm{i}}-C_{\mathrm{f}}\right)}{S}
$$

Electrochemical, Sonoelectrochemical, and Photoelectrochemical Oxidation of the Biosorption Effluents. Electrochemical oxidation experiments were carried out in a bench-scale plant with a single compartment electrochemical flow. Bulk oxidations were performed in a single-compartment cell, as described in previous works. ${ }^{24}$ BDD and steel electrodes were used as anode and cathode, respectively. Characteristics of $\mathrm{BDD}$ are as follows: $\mathrm{sp}^{3} / \mathrm{sp}^{2}$ ratio, 225 ; boron content, 500 ppm; width of the diamond layer, $2.68 \mu \mathrm{m}$. For the electrochemical flow cell, inlet and outlet were provided for effluent circulation through the reactor; the simulated effluent was stored in a thermo-regulated glass tank $\left(2000 \mathrm{~cm}^{3}\right)$ and circulated through the cell using a peristaltic pump at a flow rate of $200 \mathrm{dm}^{3} \mathrm{~h}^{-1}$. The electrical current was applied using a DC Power Supply (FA-376 PROMAX). Temperature was kept constant by means of a water bath. In the case of the photoelectrochemical process the same procedure was applied combined by UV lamp (VL-215MC (Vilber Lourmat), $\lambda=254$ $\mathrm{nm}$, intensity of $930 \mu \mathrm{W} \mathrm{cm} \mathrm{cm}^{-2}$ and energy $4.43-6.20 \mathrm{eV}$ irradiated $15 \mathrm{~W}$ directly to the quartz cover light). In the sonoelectrochemical processes an ultrasound generator was 
introduced in the tank reservoir working at $24 \mathrm{kHZ}$ or 100 $\mathrm{MHz}$.

Analytical Methods. $\mathrm{pH}$ and conductivity were measured with an InoLab WTW pH-meter and a GLP 31 Crison conductivimeter, respectively. Samples at different electrolysis, sonoelectrolysis, and photoelectrolysis times were filtered with $0.20 \mu \mathrm{m}$ Nylon filters before analysis. Oxyfluorfen and all intermediates generated were identified by HPLC-UV (Agilent 1100 series) (detection limit: $0.01 \mathrm{mg} \mathrm{dm}^{-3}$ ). The analytical column used was type Phenomenex Gemini $5 \mathrm{~lm}$ $\mathrm{C} 18$, and it was maintained at room temperature. A gradient elution was applied using the mobile phase formed by $25 \mathrm{mM}$ of formic acid water solution (Solvent A) and acetonitrile (Solvent B). A lineal gradient was obtained by initially running $10 \%$ of Solvent B ascending to $100 \%$ in $40 \mathrm{~min}$. The injection volume was $20 \mu \mathrm{L}$ and the UV detector of the HPLC-UV was operated at $291 \mathrm{~nm}$. The ionic species $\left(\mathrm{NO}_{3}{ }^{-}, \mathrm{SO}_{4}{ }^{2-}, \mathrm{Cl}^{-}\right)$ were measured by ion chromatography using a Shimadzu LC20A equipped with a Shodex IC I-524A column (anionic species); mobile phase, $2.5 \mathrm{mM}$ phthalic acid at $\mathrm{pH} 4.0$; flow rate, $1 \cdot 10^{-3} \mathrm{dm}^{3} \mathrm{~min}^{-1}$ (concentration accuracy: $\pm 0.5 \%$ ). The removal of total organic carbon (TOC) was determined with a Multi N/C 3100 Analytik Jena TOC analyzer. The particle size was measured using a Mastersizerhydro 2000SM from Malvern. $^{26}$

\section{RESULTS AND DISCUSSION}

Production of the Soil-Washing Wastewater. Surfactant-aided soil washing (SASW) is a well-known soil remediation technology. It can be used to transfer pollutants from the contaminated soil to a soil washing fluid (SWF), which has to be further treated with an efficient wastewater treatment technology to definitely remove the pollution. Hence, SASW remediates the soil and thus, it transforms the problem of soil remediation into a hypothetically easier wastewater treatment problem. Typically, the wastewater generated in this process exhibits a complex composition, which depends on the organic and inorganic species contained in the soil and also on the composition of the soil washing fluid used to extract the pollutants. For the treatment of soil polluted with nonpolar compounds, surfactants are typical components of the SWF. Consequently, the effluents obtained after the SASW treatment consist of emulsions of micelles (made of pollutant and surfactant), low concentrations of the pollutant (related with its solubility in water) and varying concentrations of free surfactant (not linked with micelles) that depend on the dose used in the soil washing processes and on the critical micellar concentration. The concentration of surfactant contained in the SWF should be high enough to warrant an efficient transfer of the pollutant from soil to water but low enough to avoid the production of a highly loaded liquid waste. For this reason, in order to reduce the organic load of washing effluents, it is necessary to determine the optimum amount of surfactant required in each case that is suitable to extract the pollutant completely but not much larger than this value.

Taking into account these comments, Figure 1 shows the amount of herbicide extracted from the soil as a function of the ratio mass of surfactant/mass of soil used in each soil-washing process.

As it can be observed, oxyfluorfen is not transferred to the liquid phase in the case of using SWF consisting of raw water or low concentrated SDS solutions. In fact, the extraction increases exponentially with the mass ratio SDS/soil. This

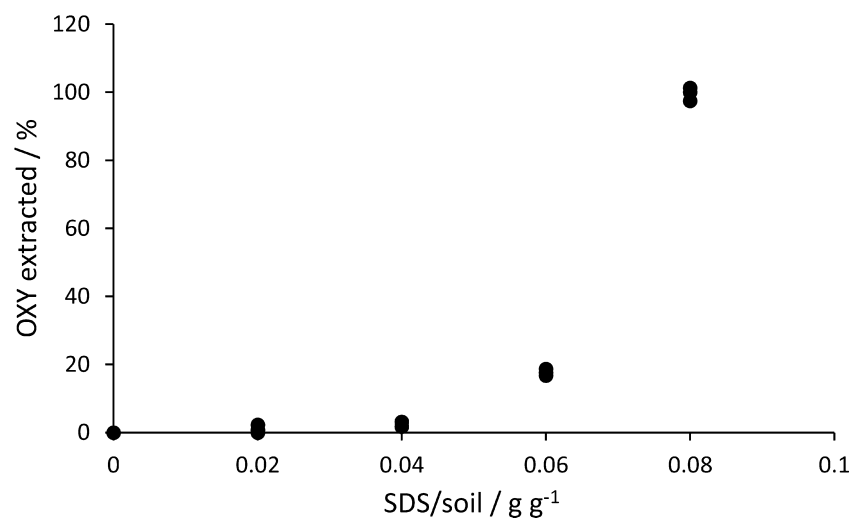

Figure 1. Oxyfluorfen extracted from soil as a function of the SDS/soil ratio.

means that soil has high retention capability and a minimum amount of surfactant must be added to start dragging the herbicide. On the basis of these results, and in order to attain $100 \%$ oxyfluorfen extraction, it was decided to use the ratio $0.08 \mathrm{~g}$ of SDS $\mathrm{g}^{-1}$ of soil to wash the polluted soil $(500 \mathrm{mg}$ oxyfluorfen $\mathrm{kg}^{-1}$ of soil). The SWF obtained after $24 \mathrm{~h}$ of washing and $1.0 \mathrm{~h}$ of sedimentation (to separate solid and liquid phases) contained $74 \mathrm{mg} \mathrm{dm}^{-3}$ of oxyfluorfen, around $2700 \mathrm{mg} \mathrm{dm}^{-3}$ of total organic carbon (TOC), and $4500 \mathrm{mg}$ $\mathrm{dm}^{-3}$ of chemical oxygen demand (COD) (most of the organic content is associated with the surfactant). As expected, the organic load of this effluent is high. However, TOC and COD values are lower than those expected taking into account the highly concentrated SDS solution used $\left(20 \mathrm{~g}\right.$ of SDS $\left.\mathrm{dm}^{-3}\right)$ and thus, this indicates that around $75 \%$ of the SDS used was retained in the soil during the soil washing procedure.

Biosorption of Soil-Washing Fluids. The effluent obtained from the washing of the polluted soil was filtered. Then, to study the herbicide removal by means of biosorption, several tests were carried out at different biomass-to-herbicide ratios (BHRs), within the range from 0 to $35 \mathrm{mg}$ biomass $/ \mathrm{mg}$ oxyfluorfen, by mixing activated sludge with the SWF for 60 min. Figure 2 shows the concentration of oxyfluorfen and COD in the effluent of this short biological treatment. It is important to remark that activated sludge was not acclimated to this

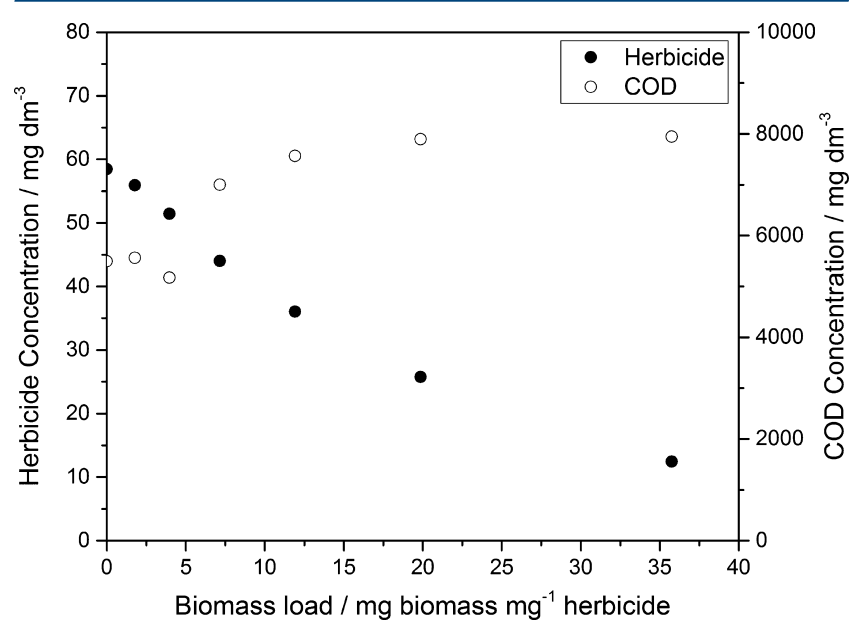

Figure 2. COD $(\bullet)$ and oxyfluorfen $(O)$ concentration of the effluent of the biosorption process obtained with different ratios of biomass/ herbicide. 
herbicide, but just used as taken from the biological reactors of a municipal wastewater treatment plant.

There is a clear influence of the BHR on the concentrations of herbicides and COD. Regarding the herbicide, the higher is the biomass dosed to the soil-washing fluid, the lower is the oxyfluorfen detected in the effluent after the biological tests. The oxyfluorfen removal fits well to an exponential decay, which explains the successful decrease of the initial concentration of more than six times with the highest BHR tested (down to $10 \mathrm{mg} \mathrm{dm}{ }^{-3}$ ). Regarding the rate of the process, it was observed that in each test most of the oxyfluorfen was removed within $45 \mathrm{~min}$ (data not shown) and then concentration stabilized. Taking into account that the biological culture was not acclimated to this type of wastewater, this rapid removal which ends up with a stabilization in the concentration indicates that almost no degradation in the biomass is taking place. Thus, in the literature, ${ }^{27,28}$ it has been reported that the biodegradation of the oxyfluorfen takes several days. Therefore, the adsorption of oxyfluorfen over the activated sludge seems to be the primary mechanism for the removal.

Regarding the concentration of COD in the effluent of the biological process, a different behavior is observed as compared to the oxyfluorfen evolution. In this case, COD increases slightly with the biomass load dosed. This increase can be explained in terms of the soluble COD of the biomass added, which obviously increases as the ratio biomass/herbicide increases.

The oxyfluorfen adsorbed onto the biomass was determined by mass balance, using the concentration of oxyfluorfen in the solution at the beginning of the experiment and once the steady state was reached. This information is plotted vs the BHR in Figure 3.

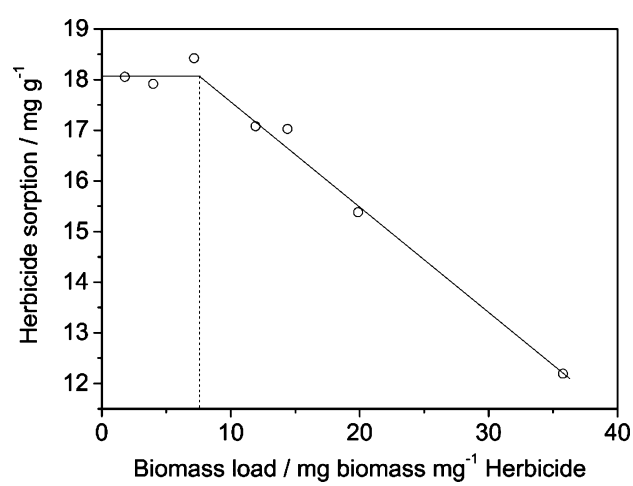

Figure 3. Effect of biomass loading on herbicide biosorption.

An increase in the HBR from 0.0 to $7.5 \mathrm{mg} \mathrm{mg}^{-1}$ apparently does not produce any herbicide removal, pointing out that a minimum concentration of biomass should be added to produce an efficient removal of the pollutant. From this value on, there is a linear decrease of the concentration of oxyfluorfen with the BHR. To understand better these results, the pseudoequilibrium isotherm was obtained and plotted in Figure 4. As mentioned before, the contact time between the herbicide and the biomass was very short, ensuring that the pseudo steady-state values reached were only due to the biosorption equilibrium and not associated with biodegradation.

Experimental data define a typical type I adsorption isotherm. These results were fitted to the Langmuir model obtaining a quite good fitting $\left(r^{2}=0.997\right)$. The maximum adsorption

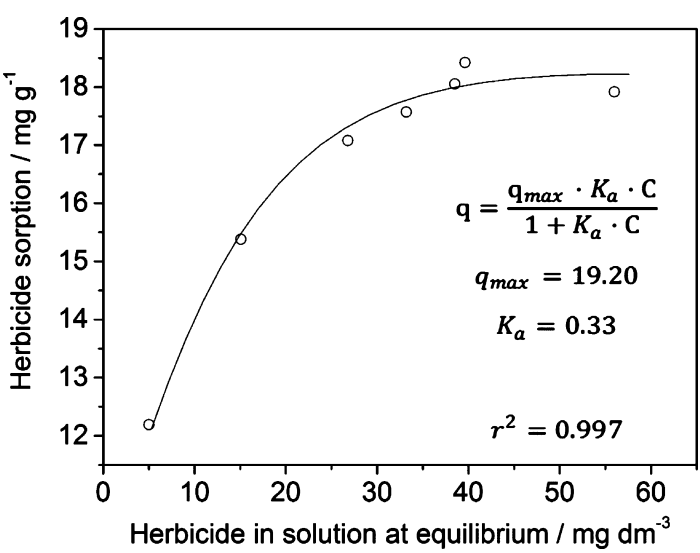

Figure 4. Equilibrium isotherm at $20^{\circ} \mathrm{C}$ of herbicide oxyfluorfen onto activated sludge biomass.

capacity was obtained for oxyfluorfen concentrations in solution higher than $40 \mathrm{mg} \mathrm{dm}^{-3}$, and was close to $18.0 \mathrm{mg}$ oxyfluorfen $\mathrm{g}^{-1}$ biomass. This specific biosorption value compares favorably with other results reported in the literature for other herbicides. ${ }^{22,29}$ However, when they are compared with the results obtained in a previous work about 2,4-D published recently by our group, they are quite similar when they are expressed in mmol $\mathrm{g}^{-1}$ biomass. Thus, the maximum adsorption capacity of the activated sludge with 2,4-D was found to be $0.054 \mathrm{mmol} \mathrm{g}^{-1}$ biomass ( $11.9 \mathrm{mg}$ oxyfluorfen $\mathrm{g}^{-1}$ biomass) while the adsorption capacity with oxyfluorfen was $0.050 \mathrm{mmol} \mathrm{g}^{-1}$ biomass.

Electrolysis of the Biosorption Effluents. Once biosorption has been checked for the removal of oxyfluorfen from SWF, the resulting effluent presented significant concentrations of herbicide and organic matter. Therefore, it is necessary to carry out a more efficient post-treatment that allow a complete removal of the herbicide and a total mineralization of the organic matter. In this context, electrochemical technologies were assessed for the treatment of the effluent from the biosorption process. Figure 5 shows the changes in pollutant concentration and TOC during the anodic oxidation (AO), photoelectrolysis (PE), and sonoelectrolysis at high (HF-SE) and low frequency (LF-SE) of the effluent of the biosorption process using a BHR of 20 .

As it can be observed, oxyfluorfen is rapidly and effectively oxidized by the four electrochemical advanced oxidation processes. Applied electric charges below $50 \mathrm{Ah} \mathrm{dm}^{-3}$ are required to decrease the concentration of herbicide more than 3 log-units from the initial $74 \mathrm{mg} \mathrm{dm}^{-3}$ down to $0.1 \mathrm{mg} \mathrm{dm}^{-3}$, regardless of the technology evaluated. In fact, data are overlapped in the four tests carried out, suggesting very small differences. These results indicate that oxyfluorfen contained in the effluent of the combined SASW-biosorption process can be very easily oxidized, as it was also found in previous studies in which the degradation of SASW effluents without the biological step were carried out. ${ }^{15,20}$ In those studies, the matrix of species was much simpler than in the present work because it did not contain the metabolites and nutrients added with the activated sludge during the biosorption stage, which could become a key difference in terms of treatability.

When the results of the application of the different EAOP are compared in terms of TOC removal, greater differences arise during the treatment, although mineralization attained at the end of the tests was almost the same for the four technologies, 


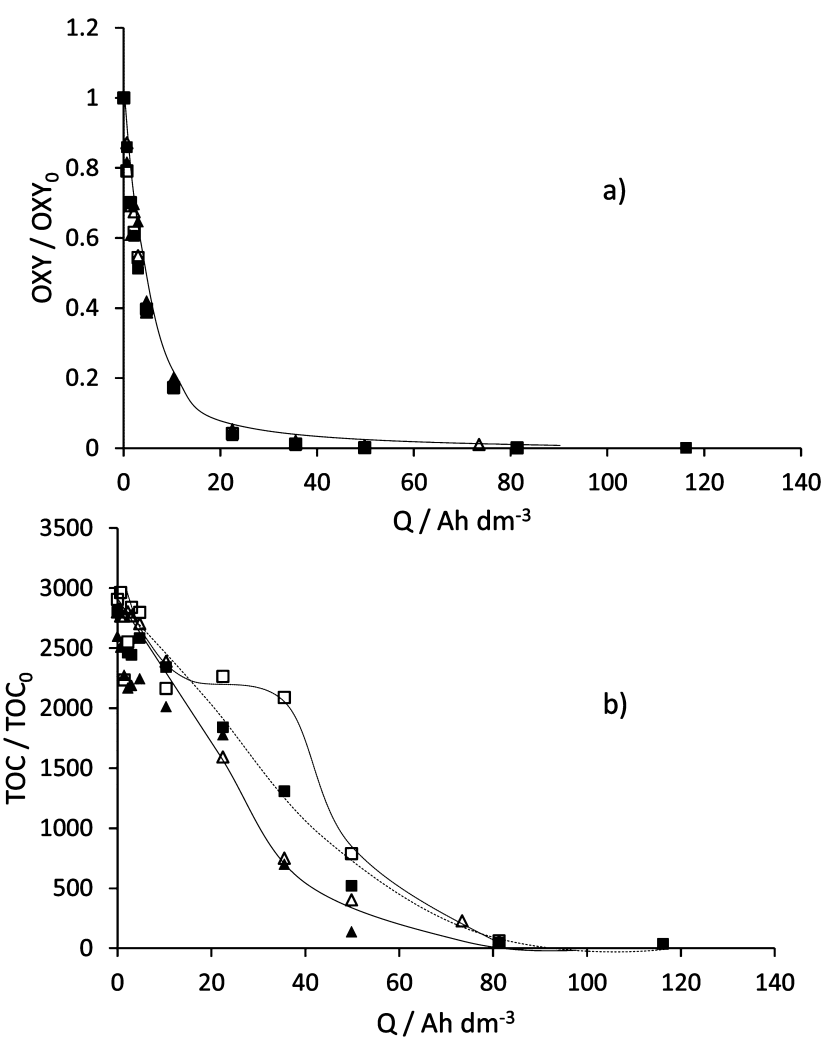

Figure 5. Changes in the oxyfluorfen concentration (a) and TOC (b) during the electrochemical treatment of the effluent of combined soil washing and bioadsorption process. ( $\boldsymbol{\square}) \mathrm{AO},(\square) \mathrm{PE},(\boldsymbol{\Delta})$ HF-SE $(\triangle)$ LF-SE. Current density, $30 \mathrm{~mA} \mathrm{~cm}{ }^{-2}$; anode, BDD; cathode, SS; $\mathrm{UV}_{254 \mathrm{~nm}}, 4 \mathrm{~W}$; US high frequency, $100 \mathrm{MHz}$; and US low frequency, $24 \mathrm{kHz}$.

meaning that all EAOPS tested lead to a similar degree of treatment at large electric charges passed. The electric charges required to attain the complete mineralization of the organic load are more than the double of those required for oxyfluorfen removal. This means that intermediates and oxidation of other species contained in the effluent of the biosorption process are important and they are affected in a different way (or with a different rate) by the different technologies evaluated.

It is important to point out that the initial TOC concentration measured (around $2700 \mathrm{mg}$ of $\mathrm{C} \mathrm{dm}^{-3}$ ) is mainly related to the presence of SDS, which is significantly higher than the carbon concentration related to oxyfluorfen (initial oxyfluorfen concentration corresponds to around $20 \mathrm{mg}$ $\mathrm{C} \mathrm{dm}{ }^{-3}$ ), and it is also higher than the concentration of soluble metabolites added with the activated sludge during the biosorption process (which totals only a few milligram per cubic decimeter of $\mathrm{C}$ ). Thus, initially the differences found between the changes observed in the pollutant removal and mineralization should be explained in terms of the degradation of surfactant molecules and also to the formation of reaction intermediates.

Regarding the surfactant, as it is known, SDS consists of a linear hydrocarbon tail attached to a sulfate group that can be easily attacked and released to the solution. Figure 6 shows the increase in the sulfate concentration during the electrochemical treatments.

It is important to remark that initially the effluent of the bioadsorption process contains a relevant amount of sulfate related to the presence of $\mathrm{MgSO}_{4}$ in the SWF used (made with
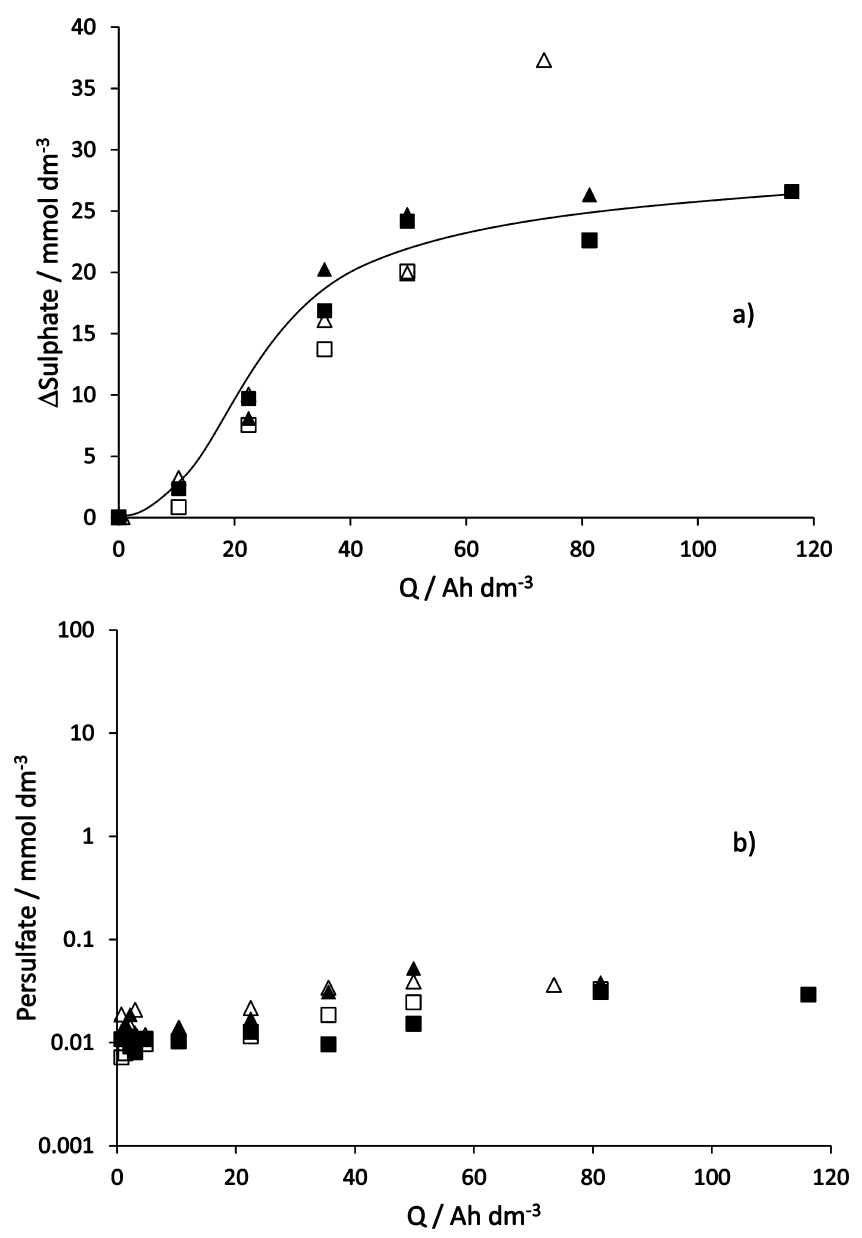

Figure 6. Concentration of sulfate ions released (a) and of persulfate generated (b) during the electrochemical treatment of the effluent of combined soil washing and bioadsorption process. ( $\square$ ) AO, ( $\square$ ) PE, $(\boldsymbol{\Delta})$ HF-SE, $(\triangle)$ LF-SE. Current density, $30 \mathrm{~mA} \mathrm{~cm}^{-2}$; anode, BDD; cathode, SS; $\mathrm{UV}_{254 \mathrm{~nm}} 4 \mathrm{~W}$; US high frequency, $100 \mathrm{MHz}$; and US low frequency, $24 \mathrm{kHz}$.

synthetic groundwater) and also to the sulfate contained in the mixed liquor of the activated sludge used. Anyway, as expected, the concentration of sulfate increases during the process indicating the attack of SDS molecule occurs, but no relevant differences are observed among the different electrochemical technologies evaluated. In addition, a very important observation that can be made is that the transformation of SDS into sulfate is quantitative (100\% transformation), and this fact supports the total mineralization of the molecule which was previously pointed out by the evolution of TOC.

Sulfate is a very important species in the electrolysis of wastewater with diamond anodes, because it is easily oxidized to peroxodisulfate, which in turn can be transformed into the sulfate radical by activation ${ }^{19,21}$ with (1) other oxidants such as hydrogen peroxide, ozone, or even other persulfate molecules, (2) UV light, or (3) ultrasounds

The concentrations of sulfate suggests that formation of this species is possible in the system. In fact, the concentration of persulfate was monitored (Figure $6 \mathrm{~b}$ ), and as observed, it varies during the treatment within $0.03 \pm 0.01 \mathrm{mmol} \mathrm{dm}^{-3}$. Regarding the sulfate radical, owing to its very short lifetime, it is difficult to observe its concentration directly (only by using mediated methods), although it may have a direct influence on the distribution of the intermediates. Obviously, its impact is 
expected to be higher in the case of irradiated EAOP, where the activation is promoted. ${ }^{30}$ In this point, it is important to remark that the effect of sulfate radicals, generated by the activation of persulfates, on the removal of organics has been previously described by elsewhere. ${ }^{31}$ In fact, differences between the different technologies are greater during the treatment, and this variability supports the interactions of the oxidant with the organic intermediates contained in the SWF which was being treated.

Figure 7 shows the changes in the concentration of different ionic species during the photo-assisted electrolytic technology
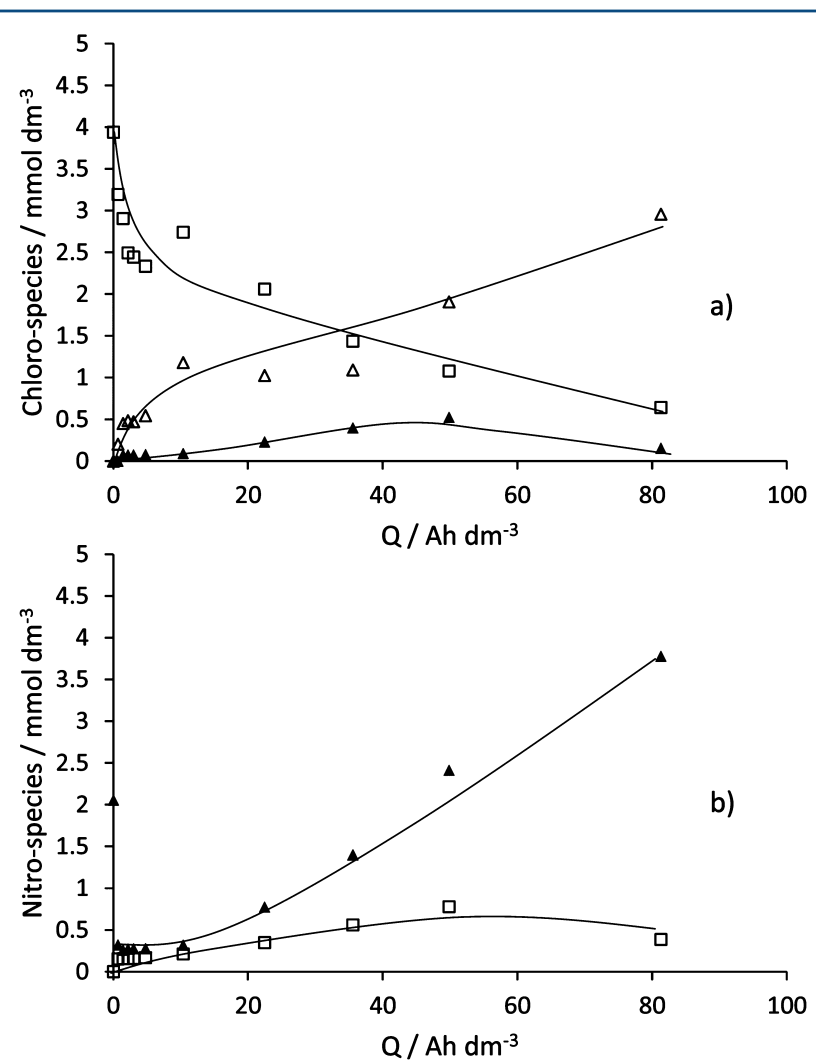

Figure 7. Concentration of chlorine-species (a) and nitro-species (b) during the electrochemical treatment of the effluent of combined soil

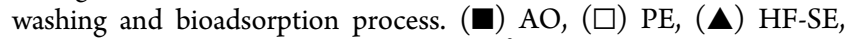
$(\triangle)$ LF-SE. Current density, $30 \mathrm{~mA} \mathrm{~cm}{ }^{-2}$; anode, BDD; cathode, SS; $\mathrm{UV}_{254 \mathrm{~nm}}, 4 \mathrm{~W}$; US high frequency, $100 \mathrm{MHz}$; and US low frequency,


$\mathrm{NH}_{4}^{+}$.

(PE). Changes in the other technologies (AO and sonoelectrolysis) are very close to those shown in this figure and hence they were not included for the sake of clarity.

As it can be observed in Figure 7a, chlorine, chlorate, and perchlorate were detected in the reaction media. As it is wellknown, chlorine is rapidly oxidized to hypochlorite which can be further oxidized during diamond-electrolysis to chlorate, and finally to perchlorate as the main final product. The concentration of hypochlorite detected in the reaction system was nil, indicating that once formed it rapidly reacts to form chlorate, to oxidize organic compounds, or even to form chloramines by reaction with ammonium ions. In fact, this can help to explain the rapid decrease observed in the concentration of ammonium ions (Figure $7 \mathrm{~b}$ ) just at the beginning of the tests. From these initial values, both ammonium and nitrate concentrations increase continuously during electrolysis. This can be related to the oxidation of the metabolites added with the activated sludge during the biosorption process. In a previous work, ${ }^{32}$ it was demonstrated that electrochemical oxidation of organic nitrogen leads directly to the formation of nitrates. These species are cathodically reduced to ammonium, which in turn can react with hypochlorite to form chloramines and finally gaseous nitrogen.

Figure 8 shows the changes in the concentration of the main intermediates detected by HPLC, produced during the tests


Figure 8. Profile of the main intermediates (quantified as chromatographic area) during the $(\boldsymbol{\square}) \mathrm{AO},(\square) \mathrm{PE},(\boldsymbol{\Delta})$ HF-SE, $(\triangle)$ LF-SE of the effluent of the combined soil washing bioadsorption process. (a) i1, (b) i2, and (c) xylene. Current density, $30 \mathrm{~mA} \mathrm{~cm}{ }^{-2}$; anode, BDD; cathode, SS; $\mathrm{UV}_{254 \mathrm{~nm}}, 4 \mathrm{~W}$; US high frequency, $100 \mathrm{MHz}$; and US low frequency, $24 \mathrm{kHz}$.

carried out with the four EAOP technologies. Only two intermediates were found and they were always the same (although in different concentrations), indicating that the primary mechanism of SDS-oxyfluorfen solutions degradation is the same, regardless the use or absence of irradiation (UV or US). However, the rates are slightly different and depend on the technology used. Likewise, in all cases they are completely degraded for electrical charges below $40 \mathrm{Ah} \mathrm{dm}^{-3}$. On the other 
hand, it is important to remark on the presence of xylene in the solution. This is not a reaction intermediate but an organic present in the commercial oxyfluorfen suspension used as raw material to pollute the soil. As can be observed, it is rapidly degraded in all cases. These results are very interesting because, in combination with those shown in Figure 5, they inform that there is a possibility of partial treatment in which a significant part of the surfactant can be recovered for further use, instead of being totally transformed into carbon dioxide as the raw herbicide and the intermediates are depleted in a moment in which there are still important amounts of SDS in solution.

At this point, it is also important to check the behavior of the emulsion of oxyfluorfen/surfactant during the combined treatment, to evaluate the breakup of the emulsion and the depletion of micelles. To assess this point, particle size distribution was measured to the final sample of each process. Figure 9 shows the particle concentration and the mean particle

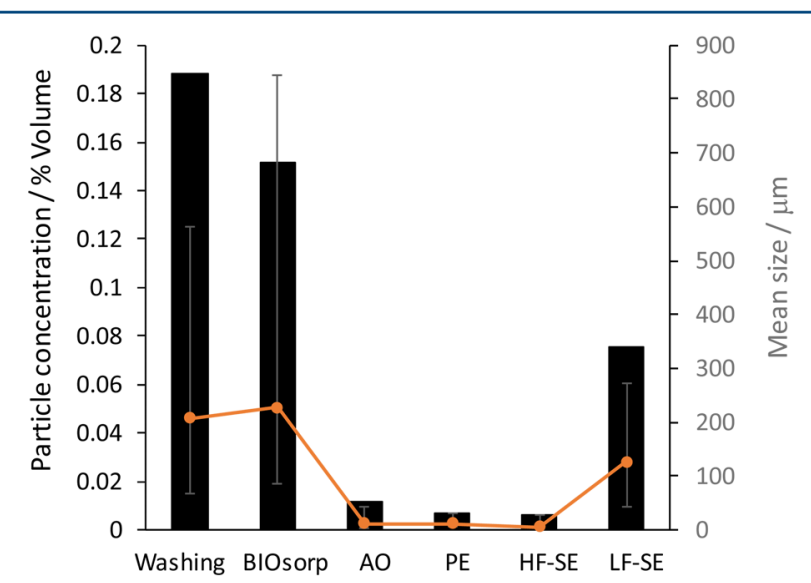

Figure 9. Particle concentration (solid bars) and mean size (discrete points) of the effluent of the different stages used in the combined process (washing+biosorption+electrochemical treatment). Current density, $30 \mathrm{~mA} \mathrm{~cm}{ }^{-2}$; anode, BDD; cathode, SS; $\mathrm{UV}_{254 \mathrm{~nm}}, 4 \mathrm{~W}$; US high frequency, $100 \mathrm{MHz}$; and US low frequency, $24 \mathrm{kHz}$.

size of the effluent after each single treatment. As it can be observed, the amount of particle does not decrease significantly during biosorption treatment and a higher dispersion in size particle is observed, which can be explained in terms of the addition of sludge flocs. In addition, mean particle size is slightly higher after this treatment. This situation reverses when electrolysis is applied and both the number of particles and the mean size decreases very importantly, The LF-SE treatment clearly being less efficient.

\section{CONCLUSIONS}

From this work, the following conclusions can be drawn:

- The use of SDS solutions are required to extract oxyfluorfen during the washing process of polluted soil. Relevant amounts of SDS are retained in the soil after the treatment.

- A rapid removal of oxyfluorfen from soil-washing fluids is attained by biosorption with a maximum adsorption capacity around $18 \mathrm{mg}$ oxyfluorfen/g biomass.

- A combination of biosorption onto activated sludge and electrochemical processes with diamond anodes can attain the complete removal of oxyfluorfen at not very high current charge applied. For this reason, reuse of SDS solution for the SWF appears promising. Higher electrical charges are required to fully degrade SDS and attain complete mineralization.

- Oxyfluorfen removal during electrochemical processes does not depend significantly on US or UV irradiation. However, marked differences are observed in the case of mineralization because intermediates removed are rapidly oxidized in the case of applying US or UV light. Release of sulfate from the oxidation of SDS, oxidation of this anion to persulfate, and activation by US or UV light can help to explain these results.

\section{AUTHOR INFORMATION}

\section{Corresponding Author}

*E-mail: Manuel.Rodrigo@uclm.es.

ORCID 우

Cristina Sáez: 0000-0001-6652-0496

Salvador Cotillas: 0000-0001-9423-5350

Manuel A. Rodrigo: 0000-0003-2518-8436

Notes

The authors declare no competing financial interest.

\section{ACKNOWLEDGMENTS}

The authors acknowledge funding support from the EU and Spanish Government through the MINECO Project CTM2013-45612-R (Electrotech4pest), CTM2016-76197-R (Sustertech4ch), FEDER 2007-2013 PP201010 (Planta Piloto de Estación de Regeneración de Aguas Depuradas), and INNOCAMPUS.

\section{REFERENCES}

(1) Rodrigo, M. A.; Oturan, N.; Oturan, M. A. Electrochemically Assisted Remediation of Pesticides in Soils and Water: A Review. Chem. Rev. 2014, 114 (17), 8720-8745.

(2) Mantzos, N.; Karakitsou, A.; Hela, D.; Patakioutas, G.; Leneti, E.; Konstantinou, I. Persistence of oxyfluorfen in soil, runoff water, sediment and plants of a sunflower cultivation. Sci. Total Environ. 2014, 472, 767-777.

(3) Sondhia, S. Persistence and bioaccumulation of oxyfluorfen residues in onion. Environ. Monit. Assess. 2010, 162 (1-4), 163-168.

(4) Sondhia, S.; Dixit, A. Persistence of oxyfluorfen residues in the soil of paddy field and detection of its residues in crop produce. Indian J. Agric. Sci. 2010, 80 (10), 926-929.

(5) Xu, L.; Wang, F.; Li, H.-Z.; Hu, Z.-M.; Guo, C.; Liu, C.-Z. Development of an efficient electroflocculation technology integrated with dispersed-air flotation for harvesting microalgae. J. Chem. Technol. Biotechnol. 2010, 85 (11), 1504-1507.

(6) Gao, S.; Du, M.; Tian, J.; Yang, J.; Yang, J.; Ma, F.; Nan, J. Effects of chloride ions on electro-coagulation-flotation process with aluminum electrodes for algae removal. J. Hazard. Mater. 2010, 182 $(1-3), 827-834$.

(7) Gao, S.; Yang, J.; Tian, J.; Ma, F.; Tu, G.; Du, M. Electrocoagulation-flotation process for algae removal. J. Hazard. Mater. 2010, $177(1-3), 336-343$.

(8) Fenoll Serrano, J.; Ruiz, E.; Hellin, P.; Lacasa, A.; Flores, P. Enhanced dissipation of oxyfluorfen, ethalfluralin, trifluralin, propyzamide, and pendimethalin in soil by solarization and biosolarization. J. Agric. Food Chem. 2010, 58 (4), 2433-8.

(9) Rodriguez-Morgado, B.; Gomez, I.; Parrado, J.; Tejada, M. Behaviour of oxyfluorfen in soils amended with edaphic biostimulants/ biofertilizers obtained from sewage sludge and chicken feathers. Effects on soil biological properties. Environ. Sci. Pollut. Res. 2014, 21 (18), $11027-11035$.

(10) Castillo Diaz, J. M.; Delgado-Moreno, L.; Nunez, R.; Nogales, R; Romero, E. Enhancing pesticide degradation using indigenous 
microorganisms isolated under high pesticide load in bioremediation systems with vermicomposts. Bioresour. Technol. 2016, 214, 234-241. (11) Chakraborty, S. K.; Bhattacharyya, A.; Chowdhury, A. Degradation of oxyfluorfen by Azotobacter chroococcum (beijerink). Bull. Environ. Contam. Toxicol. 2002, 69 (2), 203-209.

(12) Augustijnbeckers, P. W. M.; Hornsby, A. G.; Wauchope, R. D. The SCS/ARS/CES Pesticide Properties Database for Environmental Decision-Making 0.2. Additional Compounds. Rev. Environ. Contam. Toxicol. 1994, 137, 1-82.

(13) Wauchope, R. D.; Buttler, T. M.; Hornsby, A. G.; Augustijnbeckers, P. W. M.; Burt, J. P. THE SCS ARS CES Pesticide Properties Database for Environmental Decision-Making. Rev. Environ. Contam. Toxicol. 1992, 123, 1-155.

(14) dos Santos, E. V.; Saez, C.; Martinez-Huitle, C. A.; Canizares, P.; Rodrigo, M. A. Combined soil washing and CDEO for the removal of atrazine from soils. J. Hazard. Mater. 2015, 300, 129-134.

(15) dos Santos, E. V.; Saez, C.; Martinez-Huitle, C. A.; Canizares, P.; Andres Rodrigo, M. Removal of oxyfluorfen from ex-situ soil washing fluids using electrolysis with diamond anodes. J. Environ. Manage. 2016, 171, 260-266.

(16) Saez, C.; Lopez-Vizcaino, R.; Canizares, P.; Rodrigo, M. A. Conductive-Diamond Electrochemical Oxidation of Surfactant-Aided Soil-Washing Effluents. Ind. Eng. Chem. Res. 2010, 49 (20), 96319635.

(17) Bhatti, H. N.; Sadaf, S.; Aleem, A. Treatment of Textile Effluents by Low Cost Agricultural Wastes: Batch Biosorption Study. J. Animal Plant Sci. 2015, 25 (1), 284-289.

(18) Ay, C. O.; Ozcan, A. S.; Erdogan, Y.; Ozcan, A. Characterization of Punica granatum L. peels and quantitatively determination of its biosorption behavior towards lead(II) ions and Acid Blue 40. Colloids Surf., B 2012, 100, 197-204.

(19) Sirés, I.; Brillas, E.; Oturan, M. A.; Rodrigo, M. A.; Panizza, M. Electrochemical advanced oxidation processes: today and tomorrow. A review. Environ. Sci. Pollut. Res. 2014, 21, 8336.

(20) Vieira Dos Santos, E.; Sáez, C.; Cañizares, P.; Martínez-Huitle, C. A.; Rodrigo, M. A. Treating soil-washing fluids polluted with oxyfluorfen by sono-electrolysis with diamond anodes. Ultrason. Sonochem. 2017, 34, 115-122.

(21) Martinez-Huitle, C. A.; Rodrigo, M. A.; Sires, I.; Scialdone, O. Single and Coupled Electrochemical Processes and Reactors for the Abatement of Organic Water Pollutants: A Critical Review. Chem. Rev. 2015, 115 (24), 13362-13407.

(22) Chair, K.; Bedoui, A.; Bensalah, N.; Fernández-Morales, F. J.; Sáez, C.; Cañizares, P.; Rodrigo, M. A. Combining bioadsorption and photoelectrochemical oxidation for the treatment of soil-washing effluents polluted with herbicide 2,4-D. J. Chem. Technol. Biotechnol. 2017, 92 (1), 83-89.

(23) López-Vizcaíno, R.; Sáez, C.; Cañizares, P.; Rodrigo, M. A. The use of a combined process of surfactant-aided soil washing and coagulation for PAH-contaminated soils treatment. Sep. Purif. Technol. 2012, 88, 46-51.

(24) López-Vizcaíno, R.; Alonso, J.; Cañizares, P.; León, M. J.; Navarro, V.; Rodrigo, M. A.; Sáez, C. Electroremediation of a natural soil polluted with phenanthrene in a pilot plant. J. Hazard. Mater. 2014, 265, 142-150.

(25) López-Vizcaíno, R.; Alonso, J.; Cañizares, P.; León, M. J.; Navarro, V.; Rodrigo, M. A.; Sáez, C. Removal of phenanthrene from synthetic kaolin soils by eletrokinetic soil flushing. Sep. Purif. Technol. 2014, 132, 33-40.

(26) Santos, E. V. D.; Sáez, C.; Martínez-Huitle, C. A.; Cañizares, P.; Rodrigo, M. A. The role of particle size on the conductive diamond electrochemical oxidation of soil-washing effluent polluted with atrazine. Electrochem. Commun. 2015, 55, 26-29.

(27) Ferro, S.; De Battisti, A.; Duo, I.; Comninellis, C.; Haenni, W.; Perret, A. Chlorine evolution at highly boron-doped diamond electrodes. J. Electrochem. Soc. 2000, 147 (7), 2614-2619.

(28) Guinea, E.; Arias, C.; Cabot, P. L.; Garrido, J. A.; Rodriguez, R. M.; Centellas, F.; Brillas, E. Mineralization of salicylic acid in acidic aqueous medium by electrochemical advanced oxidation processes using platinum and boron-doped diamond as anode and cathodically generated hydrogen peroxide. Water Res. 2008, 42 (1-2), 499-511.

(29) Al-Malack, M. H.; Siddiqui, M. Treatment of synthetic petroleum refinery wastewater in a continuous electro-oxidation process. Desalin. Water Treat. 2013, 51 (34-36), 6580-6591.

(30) Araújo, D. M. D.; Cotillas, S.; Sáez, C.; Cañizares, P.; MartínezHuitle, C. A.; Rodrigo, M. A. Activation by light irradiation of oxidants electrochemically generated during Rhodamine B elimination. J. Electroanal. Chem. 2015, 757, 144-149.

(31) Cotillas, S.; de Vidales, M. J. M.; Llanos, J.; Sáez, C.; Cañizares, P.; Rodrigo, M. A. Electrolytic and electro-irradiated processes with diamond anodes for the oxidation of persistent pollutants and disinfection of urban treated wastewater. J. Hazard. Mater. 2016, 319, 93-101.

(32) Martin de Vidales, M. J.; Millan, M.; Saez, C.; Canizares, P.; Rodrigo, M. A. What happens to inorganic nitrogen species during conductive diamond electrochemical oxidation of real wastewater? Electrochem. Commun. 2016, 67, 65-68. 